\title{
Tecnologias digitais, subjetividade e psicopatologia: possíveis impactos da pandemia
}

\section{Digital technologies, subjectivity and psychopathology: possible impacts of the pandemic}

Benilton Bezerra Jr.*1

O artigo aborda o uso de tecnologias digitais na psiquiatria atual, discutindo o impacto dos dispositivos técnicos no horizonte social para além dos limites da clínica, focando a análise no projeto de fenotipagem digital, seu alcance, e nos desafios que ele suscita para o campo psiquiátrico.

Palavras-chave: Fenotipagem digital, tecnologias e subjetividade, psiquiatria computacional, diagnóstico

${ }^{* 1}$ Universidade do Estado do Rio de Janeiro - UERJ (Rio de Janeiro, RJ, Brasil). 


\section{Tecnologias e subjetividade}

Na história das sociedades é o impacto que certos acontecimentos têm sobre a experiência humana, mais do que o calendário oficial, que marca a passagem do tempo. Como escreveu Hobsbawn (1994), o século XX só começou de fato com o desencadeamento da I Guerra Mundial, que redesenhou de maneira radical os mapas e a distribuição de forças no tabuleiro geopolítico do globo, e terminou mais cedo do que o previsto quando, em 1991, com o fim da URSS toda uma época ficou para trás.

Cinco meses após a deflagração da pandemia, vai ficando claro que, muito provavelmente, o ano de 2020 marcará, no futuro, uma virada histórica semelhante. O século XXI, em gestação desde os anos 1990, parece estar começando efetivamente agora, com a emergência de um novo horizonte antropológico, um campo de possibilidades inédito - e um conjunto de novos problemas para a humanidade. Muitos fatores contribuem para esse processo, mas talvez o mais decisivo deles seja a expansão progressiva, para todo o universo social, dos impactos da revolução tecnológica digital — um movimento que não foi causado, mas foi fortemente acelerado pela resposta global à pandemia.

Tecnologias sempre estiveram na base de transformações profundas na condição humana, numa via de mão dupla. Isso porque ao expandir os recursos cognitivos e a capacidade de agir dos humanos, elas transformam a relação dos sujeitos com o tempo e o espaço, revolucionam as formas de convivência social, alteram profundamente a relação com o corpo, a natureza e o ambiente cultural. As tecnologias que criamos afetam nossa biologia, nossas concepções do que é a realidade, nossa experiência do que é ser um humano. Inventamos coisas e somos de volta reinventados por elas (Ramirez, 2020).

O uso sistemático do fogo para cocção de alimentos foi determinante para o crescimento da massa encefálica e o aumento dos neurônios do homo erectus, ancestral do homo sapiens. O surgimento e a difusão do relógio mecânico no século XIV marcou a passagem do "tempo da Igreja" ao "tempo do mercador" — o tempo, que era natural, 
cíclico e pertencia a Deus, passou a ser mecânico, linear e propriedade do homem - a pontualidade foi inventada, tempo virou dinheiro. A luneta usada por Galileu deslocou o lugar de Deus, da Terra e do homem no universo. A aparição da imprensa revolucionou o processo de difusão de pensamentos e histórias, conectando corações e mentes de forma inédita. $\mathrm{O}$ raio $\mathrm{X}$ transformou a relação entre exterior-visível e interior-invisível no corpo humano. O telégrafo e o telefone modificaram a experiência da distância e o estilo das comunicações. O surgimento dos psicofármacos mudou nossa relação com a loucura. Cada inovação tecnológica produz, ao mesmo tempo, transformações objetivas e subjetivas. Seu impacto não é, assim, apenas instrumental, ela reconfigura nossa visão da realidade, remodela a maneira como nos experimentamos - o modo como nos reconhecemos, os valores que cultivamos, as formas de gozar e de sofrer.

Mas nada na história se compara aos efeitos da revolução provocada pela articulação crescente entre internet, inteligência artificial e Big Data. Em 20 anos, a internet e os dispositivos digitais tornaram-se verdadeiras extensões de nossa vida mental, e uma prova simples desse fenômeno é a transformação radical da experiência e do exercício da memória. Reter informação deixou de ser algo decisivo, na medida em que a memória de tudo está disponível, imediatamente, na ponta dos dedos. A função de retenção é cada vez mais terceirizada para dispositivos externos acessíveis e confiáveis. Delegamos cada vez mais a smartphones e nuvens coisas que antes solicitávamos de áreas corticais de nosso cérebro.

\section{O fenótipo digital}

Há pouco mais de 20 anos, Andy Clarck e David Chalmers (1998) propuseram a noção de mente estendida. Para os autores, ao contrário do que dizem teorias tradicionais, a separação entre mente, corpo e ambiente é, em princípio, insustentável, na medida em que objetos do mundo externo podem fazer parte de processos cognitivos ou da identidade pessoal e, dessa maneira, funcionam como elementos integrantes do funcionamento mental. É exatamente o que testemunhamos no cotidiano atual com o uso cada vez mais intenso dos dispositivos digitais que mediam nossa relação com o ambiente e com os outros.

A ideia de mente estendida guarda uma relação com a introdução, feita anos antes por Richard Dawkins (1982), do conceito de fenótipo estendido — a ideia de que fenótipos não deveriam ser vistos apenas como processos 
biológicos, mas estendidos a todos os efeitos que um gene tem sobre seu ambiente, dentro ou fora do organismo individual. No famoso exemplo que ele oferece, dos diques construídos por castores comporiam seu fenótipo estendido.

Em 2015, um artigo publicado na Nature Biotechnology (Jain et al., 2015) propuseram uma ampliação desse conceito de Dawkins, que chamaram de fenótipo digital. Com o crescimento e evolução dos dispositivos digitais (smartphones, redes sociais, fóruns, comunidades online, dispositivos móveis de monitoramento como relógios digitais etc.), a interação dos indivíduos entre si e com os objetos do mundo produz de forma constante uma massa de dados cujo tratamento computacional permite reconfigurar de forma profunda a abordagem dos problemas de saúde, do diagnóstico ao tratamento, passando pela prevenção, detecção de fatores de risco e monitoramento do cuidado prolongado. O rastreamento contínuo e em larga escala dos dados produzidos de forma passiva, constante e remota permitiria sobretudo a detecção precoce de problemas, identificando sintomas muito antes de sua expressão fenotípica clássica, e potencialmente abrindo caminho para intervenções terapêuticas mais rápidas e bem dirigidas.

Mais do que fazer em larga escala o que os humanos sabem fazer, essas tecnologias - por atuarem de forma automática, anônima e impessoal, se mostram capazes de realizar o que os humanos não conseguem fazer, ao removerem a consciência e a contingências subjetivas, tanto do médico quanto do paciente, do processo. Ao se processarem de forma contínua, à distância, e no contexto de vida real do indivíduo, acumulam informações impossíveis colhidas de maneira episódica e espacialmente restrita, como ocorre nas consultas e pesquisas. Computadores já fazem diagnóstico de imagens com uma precisão muito maior do que médicos são capazes. Algoritmos aprendem a identificar emoções, por exemplo, a partir de padrões de microexpressões faciais dificilmente detectáveis pelo olho humano, ou a flagrar inclinações afetivas ou políticas a partir dos padrões de uso de softwares e do estilo de navegação na rede.

A fenotipagem digital é definida como a quantificação momento a momento do fenótipo humano no nível individual em seu próprio ambiente, por meio de aplicativos em celulares e outros dispositivos pessoais (Barnett et al., 2018). Essa quantificação abarca o uso de várias métricas, que incluem dados referentes à atividade do usuário e a sua localização física, padrões de voz e estrutura do discurso (prosódia, sintaxe e conteúdo), interações entre o usuário e seus dispositivos (dinâmica de uso de teclados, padrões de busca 
na internet, número e duração de chamadas, extensão e ritmo de mensagens, frequência de presença nas redes sociais etc. (Insel, 2018).

A acolhida no campo psiquiátrico à revolução digital não se fez esperar. A trajetória de Thomas Insel, diretor durante 13 anos, a partir de 2002, do prestigiado NIMH - o Instituto Nacional de Saúde Mental americano é, nesse ponto, particularmente eloquente. Em 2013, pouco antes do lançamento do DSM-5 pela American Psychatric Association (APA), Insel (2013) provocou enorme mal-estar no meio psiquiátrico ao publicar um post em seu blog oficial acusando o novo manual de não possuir validade cientifica, por se basear em critérios clínicos e não laboratoriais, razão pela qual anunciava que o NIMH iria se afastar do DSM, reorientando suas pesquisas para um alinhamento com o recém-criado $\mathrm{RDoC}$, em busca de marcadores biológicos que permitissem a almejada constituição de uma psiquiatria cientificamente fundada. $\mathrm{O}$ tom agressivo da crítica ("os pacientes com transtornos mentais merecem coisa melhor") e a defesa contundente do paradigma biológico ("transtornos mentais são transtornos biológicos envolvendo circuitos cerebrais que implicam domínios específicos de cognição, emoção ou comportamento") não fariam adivinhar seus movimentos seguintes.

Em 2015, Insel pede demissão do cargo e é contratado pela Google para alavancar uma startup de tecnologia em saúde com foco em fenotipagem digital (Verily). Em 2017 deixa a Google para criar sua primeira empresa, a Mindstrong, e mais outra no início de 2020, a NEST Health. A ênfase na pesquisa neurobiológica como estratégia para construção de uma "medicina de precisão para a psiquiatria" (Insel, 2014), dá lugar a outra retórica: "O que o campo necessita é de um dispositivo objetivo, passivo e ubíquo para capturar de forma contínua informação comportamental e cognitiva" (2017, p. 1215). Apesar da importância para a psiquiatria das revoluções na genômica e nas neurociências, agora "é a revolução na ciência e nas tecnologias de informação que terá mais consequências para a saúde mental global” (2018, p. 276).

De fato, nos últimos cinco anos o uso de estruturas matemáticas, ferramentas digitais, e processamento computacional na psiquiatria tem crescido exponencialmente, com resultados impressionantes. No Brasil, é particularmente notável o trabalho de Mota, Copelli e Ribeiro (2017, 2019) que, por meio da análise de relatos curtos de sonhos de pacientes, que são gravados, transcritos e representados como grafos de palavras, conseguiram detectar desorganizações no discurso de pacientes, possibilitando o diagnóstico precoce de esquizofrenia, com precisão de mais de 90\%. 
A utilização do conceito de fenotipagem digital tem sido cada vez mais frequente em. pesquisas voltadas não só para a esquizofrenia (Barnett et al., 2018; Bedi et al., 2015), mas também para transtornos do humor (Brietzke et al., 2019), ideação suicida (Kleiman et al., 2018), Alzheimer (Sperling, 2014), transtornos de personalidade (Carvalho \& Pianowski, 2017), depressão (Jacobson et al., 2019), e assim por diante. O projeto de fenotipagem digital já chama atenção até mesmo de psicanalistas (Potier, 2020).

Não há dúvida que esse é um caminho sem volta. A digitalização da psiquiatria acompanha um movimento que ultrapassa o campo da saúde e encompassa praticamente todos os aspectos da vida social. Por isso mesmo, ao lado do empenho em explorar as novas possibilidades que esse processo encerra, é urgente abrir uma discussão ponderada sobre os seus efeitos — os esperados e os inesperados — não só sobre a prática clínica, mas também sobre a vida subjetiva como um todo.

Em um artigo publicado recentemente, Stanghellini e Leoni (2020) exploram justamente o que consideram as ameaças da fenotipagem digital e as maneiras pelas quais ela pode reconfigurar nossa experiência do corpo e nossa forma de pensar. Os autores partem da premissa de que a medicina e a psiquiatria possuem uma dimensão antropológica inescapável, já que os conceitos e tecnologias que acionam têm intrinsecamente um poder que ultrapassa os limites restritos de seu uso clínico e exerce efeitos inevitáveis na vida subjetiva individual e coletiva. Tecnologias inovadoras têm o potencial para criar um novo conjunto de conceitos, objetos e práticas, redefinindo todo um campo de possibilidades e impossibilidades para a existência humana.

Com as tecnologias digitais e a psiquiatria computacional, surge um novo campo epistêmico. Onde havia um objeto, existe agora um processo. $\mathrm{O}$ diagnóstico, que antes se voltava para a descoberta de algo estável e contido no espaço, se volta agora para o monitoramento de um conjunto de variáveis que flutuam no tempo e se distribuem difusamente no espaço. Com o uso das novas tecnologias, as polaridades axiais do modelo anterior - interior/ exterior, visível/invisível, primeira/terceira pessoa, etiologia/semiologia, causa/efeito — têm sua relevância bastante diluída.

É a própria natureza do instrumento técnico que desloca o campo epistêmico noutra direção. O clínico digital não está voltado para a busca por uma etiologia objetiva situado no corpo material, como ambiciona o naturalismo biológico do RDoC, por exemplo. O que lhe interessa é compreender a covariância entre variáveis escolhidas para observação num corpo digitalizado. Quanto mais informação for possível acumular com a 


\section{ARTIGOS}

fenotipagem digital, menos relevante será o paradigma causal. A exploração do sentido no relato da experiência feito na primeira pessoa em situação relacional (segunda pessoa) tampouco acrescenta dados ao empreendimento. O que importa é monitorar processos para identificar fatores de risco, não determinantes causais; fazer predições, e não fornecer explicações causais ou compreensão psicológica. Como dizem os autores, nesse enquadre somos levados a "focar em corpos desmaterializados, imagens, algoritmos, processos, covariância etc., em vez de corpos físicos, palavras, histórias pessoais, eventos discretos, causas e razões" (p. 3).

É importante lembrar que essa é uma tendência que atinge profissionais de saúde, claro, mas também a população em geral. $\mathrm{O}$ impacto a longo prazo da digitalização não se restringirá apenas a um campo técnico, mas atingirá fortemente o imaginário social, a maneira como espontaneamente concebemos e identificamos o que sejam saúde e doença. E se essa tendência atinge em cheio o diagnóstico, também incidirá inevitavelmente sobre a maneira como conceituamos o que devem ser as intervenções terapêuticas. É fácil imaginar que a ideia da clínica como campo de exploração do sentido pessoal ou da causa biológica da experiência de sofrimento ceda lugar para uma prática de controle e balanceamento e equalização de funcionamentos desviantes, atípicos ou inesperados. Assim como ocorre com o apelo das ideias de causa e razão enquanto operadoras da clínica, também a noção de pathos como experiência definidora essencial no conceito de patologia tende a perder inteiramente seu valor.

Neste ponto os autores, sem entrar a fundo na discussão, lançam uma questão fundamental: pode a fenotipagem digital ajudar na distinção entre normalidade e patologia? A pergunta é, na verdade, um divisor de águas fundamental no campo da clínica. De um lado estão os naturalistas, que, como Boorse (1977), acreditam ser possível estabelecer conceitos objetivos, valorativamente neutros, de saúde e doença. Para esses, a desmaterialização digital da medicina provoca pouca discussão. De outro, se encontram os normativistas dos quais Canguilhem (1943/2002) é o expoente máximo. Para esses, ao contrário, há questões fundamentais que precisam ser reativadas. Para o filósofo da medicina francês, a definição das fronteiras entre normalidade, atipia e patologia não podem ser definidas de modo objetivo, pela aferição de médias estatísticas. Um funcionamento, uma condição, ou um estado, só são patológicos na medida em que atinjam negativamente a normatividade inerente ao organismo. É esta apreciação valorativa, que sempre exige atenção ao contexto e à singularidade individual, que diferencia o que é o limite entre 
a saúde e a doença. A mera diferença em relação a padrões estatísticos preestabelecidos de normalidade não é signo de doença. Desse modo, o uso na medicina de instrumentos de monitoramento como a fenotipagem digital para diagnóstico depende, para sua eficácia, de uma definição prévia do que seja a fronteira entre saúde e doença. E esta demarcação exige uma perspectiva normativa. O pathos importa, não importa o que dados objetivos mostrem.

\section{O mundo físico-digital}

O processo de crescente fusão entre os mundos físico e virtual tem um impacto profundo e duradouro. Na verdade, parece apontar para o fim próximo do modo de conceber e experimentar a condição humana que se iniciou com a modernidade. Danny Hillis (2016) descreve esse processo como a passagem da era do Iluminismo para a era do Entrelaçamento.

Em suas palavras, na era do Iluminismo inventamos a ciência e, com ela, passamos a compreender as leis da natureza, a predizer e manipular fenômenos. Ampliamos nossas capacidades naturais, inventamos instrumentos, criamos plantas e animais que não existiam, dominamos o tempo, encurtamos o espaço. Aprendemos a separar cultura e natureza, mente e matéria, causa e efeito. O desencantamento do mundo colocou a humanidade numa posição de controle da natureza e comando de seu destino. Para Hillis, esse processo chegou a seu ápice com o surgimento dos computadores digitais, "as catedrais do Iluminismo, a última expressão do controle determinístico" (p. 3). Com o universo digital em expansão, estamos cada vez mais entrelaçados com as tecnologias e, por meio dos sistemas de interação que elas propiciam, uns com os outros. Mas o poder alcançado pelos dispositivos digitais e pela inteligência artificial começa a ultrapassar a capacidade de nossas próprias mentes, e à medida que nossas tecnologias e instituições se tornam mais complexas, nossa relação com elas muda. Estamos cada vez mais nos relacionando com elas do jeito que nos relacionávamos com a natureza antes de sermos modernos, aprendendo a negociar com elas em vez de simplesmente controlá-las: "Nós construímos nossa própria selva, e ela tem vida própria" (ibidem). Treinamos máquinas para melhor manipulá-las, mas quanto mais elas nos conhecem, mais são capazes de nos manipular de volta.

O significado profundo desse processo tem sido avaliado de maneiras muito distintas. Tecnofílicos e tecnocríticos se distribuem nas análises do fenômeno. Para Lévy (2000), por exemplo, a revolução digital carrega em si 


\section{ARTIGOS}

mesma uma potência emancipatória. Com o acesso universal aos sistemas de informação, a descentralização dos dispositivos interativos e comunicação, a liberdade na construção de redes, e as possibilidades ampliadas de mobilização coletiva de grupos antes marginalizados, o cyberespaco e a cultural digital engendrariam menores efeitos de exclusão e abririam um horizonte mais amplo de exercício político, situando os sujeitos na condição de cidadãos do mundo.

Outros, como Bauman (2001, 2014), veem o cenário com mais preocupação. Para ele, a vigilância é o elemento-chave do exercício do poder no mundo moderno, e as tecnologias digitais desempenham um papel crucial nas suas novas formas - suaves e tentaculares - de estruturação. A vigilância tornada líquida cresce mais como uma erva daninha do que como uma árvore, para usar a imagem de Deleuze na análise da sociedade de controle. A arquitetura e a dinâmica das tecnologias eletrônicas, que envolvem Big Data, algoritmos e indivíduos produzindo voluntariamente informações sobre si próprios permitem uma nova transparência em que todos somos permanentemente vasculhados, monitorados, testados, e persuadidos - a realidade da submissão e do controle travestida de experiência de autonomia e liberdade. Essa seria a característica mais decisiva das transformações na vida social que as tecnologias digitais vêm precipitando.

Esse é também, para Byung-Chul Han (2014, 2017), o cerne do cenário político-subjetivo atual. A sensação de liberdade propiciada pelo uso das tecnologias de informação e comunicação universalmente disponíveis se transforma numa das formas mais eficientes de subjetivação e assujeitamento. Hoje não nos enxergamos como sujeitos (assujeitados), mas como projetos livres que se questionam e se reinventam constantemente. No panóptico digital não há prisioneiros. Seu elemento fundamental é a ilusão de liberdade. No mundo da psicopolítica, o controle não encontra barreira quando a autoexibição não decorre de constrangimentos externos, mas de movimentos vividos como expressão de legítimos anseios e impulsos internos. O Big Brother deu lugar ao Big Data.

Neste cenário não parece haver alternativas para a psiquiatria. Ela precisa se ajustar ao horizonte tecnológico dos tempos atuais e nele encontrar o caminho para fazer face aos desafios que seu mandato social lhe impõe. Isso implica descobrir formas de utilizar as tecnologias digitais para aperfeiçoar suas estratégias de prevenção, diagnóstico, tratamento e reabilitação, tornando sua atuação mais precoce, mais precisa, mais objetivamente avaliável, mais segura, mais confiável, mais eficaz. 
Mas, como Hillis alerta, há um perigo à espreita nessa empreitada. As tecnologias que criamos estão se tornando cada vez mais capazes de produzir efeitos para além daqueles visados na sua criação. A câmera, o smartphone, os processadores e os algoritmos não foram criados com a intenção de construir uma rede de vigilância e controle universais, mas isso acabou acontecendo. O gigantesco sistema tecnológico que criamos não tinha intenções filosóficas, mas está transformando profundamente a maneira como concebemos e experimentamos a experiência de ser um humano, os sentidos que atribuímos a coisas como satisfação, prazer e sofrimento. E um dos efeitos dessa transformação é uma espécie de mesmerização pela ciência e a tecnologia, a quem tendemos a delegar uma legitimidade incontida para tratar das questões referentes à "vida", ao "mundo" e à "saúde".

Para a psiquiatria, há oportunidade e risco nesse horizonte. A oportunidade está na possibilidade que o cenário digital oferece de possibilitar ampliação de acesso ao cuidado, tanto com intervenções precoces quanto com monitoramento continuado, aprimoramento dos recursos diagnósticos com acionamento de métodos objetivos refinados e confiáveis para complementar avaliações qualitativas de experiências de sofrimento psíquico, multiplicação de recursos terapêuticos autogeridos, e assim por diante.

Os riscos podem ser situados pelo menos em dois âmbitos $\mathrm{O}$ primeiro, já assinalado, pode ser identificado nas necessárias limitações metodológicas do projeto de fenotipagem digital que, por definição, excluem a dimensão da singularidade subjetiva e o contexto cultural. O grafo individual resultante da fenotipagem é certamente útil e decisivo nas estratégias diagnósticas e no estabelecimento de estratégias de atenção, mas não substitui a singularidade que decorre dos sentidos que cada sujeito constrói a partir de sua economia psíquica pessoal. Na verdade, quanto mais ricos são os resultados das abordagens digitais, mais elas iluminam o espaço deixado metodologicamente vazio - mas que precisa ser teórica e clinicamente abordado — da questão fundamental do sujeito.

O outro âmbito que as tecnologias ressaltam como objeto urgente de reflexão é mais amplo, e diz respeito ao modo como o impacto delas no mundo contemporâneo põe em questão a própria natureza da sociedade que vimos construindo nos últimos séculos. Desde a Modernidade vimos consolidando uma visão da sociedade fortemente ancorada numa relação com a natureza como objeto de conquista, controle e exploração para o bem da humanidade - relação que, embora nos permita em breve conquistar as estrelas e quebrar a caixa preta da vida, é responsável pela inegável crise 
civilizatória e planetária na qual estamos mergulhados, e da qual a pandemia é uma expressão. Como alerta o filósofo chinês Yuk Hui (2017), é necessário reabrir a questão da tecnologia a fim de tornar viável a bifurcação de futuros tecnológicos possíveis - concebendo o que chama de "cosmotécnica", que recupere a essência poiética ou geradora da técnica, superando sua concepção meramente instrumental ou de enquadramento que a modernidade reservou para elas, e abrindo espaço para a emergência de uma nova cosmopolítica. Reabrir a questão da tecnologia significa recusar a ideia de que o futuro tecnológico homogêneo que o estado atual das coisas prenuncia seja a única opção, e assumir que "é a questão de 'viver', e não a técnica, que está no centro da história".

Talvez esses sejam bons começos para avaliar as consequências e os desafios que as tecnologias digitais oferecem hoje à psiquiatria.

\section{Referências}

Bauman, Z., \& Lyon, D. (2001). Modernidade líquida. Rio de Janeiro, RJ: Zahar.

Bauman, Z., \& Lyon, D. (2014) Vigilância líquida. Rio de Janeiro, RJ: Zahar.

Barnett, I., Torous, J., Staples, P., Sandoval, L., Keshavan, M., \& Onnela, J. P. (2018). Relapse prediction in schizophrenia through digital phenotyping: a pilot study. Neuropsychopharmacology. 43 (July 8), 1660-1666.

Bedi, G., Carrillo, F., Cecchi, G. A. et al. (2015). Automated analysis of free speech predicts psychosis onset in high-risk youths [published online August 26, 2015]. NPJ Schizophr. doi:10.1038/npjschz.2015.30

Boorse, C. (1977). Health as a theoretical concept. Philosophy of Science 44, 542$-573$.

Brietzke, E. et al. (2019). Integrating digital phenotyping in clinical characterization of individuals with mood disorders. Neuroscience \& Biobehavioral Reviews, 104, 223-230.

Canguilhem, G. (2002). O normal e o patológico. Rio de Janeiro, RJ: Forense Universitária. (Trabalho original publicado em 1943).

Carvalho, L. F., \& Pianowski, G. (2017). Pathological personality traits assessment using Facebook: Systematic review and meta-analyses. Computers in Human Behavior, 71, 307-317. doi:10.1016/j.chb.2017.01.061

Clarck, A., \& Chalmers, D. (1998). The Extended Mind Analysis 58, 1, 7-19.

Dawkins, R. (1982). The Extended Phenotype. Oxford, UK: Oxford University Press. 
Han, B. C. (2014) Psicopolítica: Neoliberalismo y nuevas técnicas de poder. 2014, Barcelona, ESP: Herder Editorial S.L.

Han, B. C. (2017). Sociedade da transparência. Petrópolis, RJ: Vozes.

Hillis, D. (2016). The Enlightenment is Dead, Long Livre the Entanglement. Journal of Design and Science. <https://doi.org/10.21428/1a042043>.

Hobsbawn, E. (1994). Era dos extremos - o breve século XX: 1914-1991. São Paulo, SP: Companhia das Letras.

Hui, Y (2017). https://www.e-flux.com/journal/86/161887/cosmotechnics-ascosmopolitics/

Insel, T. R. (2013, Apr.). NIMH Director's Blog: Transforming Diagnosis. 29 April 2013. Recuperado em 15 mar. 2014 de: <http://www.nimh.nih.gov/about/ director/2013/transforming-diagnosis.shtml $>$.

Insel, T. R. (2014). The NIMH Research Domain Criteria (RDoC) project. Am J Psychiatry. 171(4), 395397.

Insel, T. R. (2017). Digital Phenotyping - Technology for a New Science of Behavior. JAMA, 318(13), 1215. doi:10.1001/jama.2017.11295.

Insel, T. R. (2018). Digital phenotyping: a global tool for psychiatry. World Psychiatry, 17(3), 276-277. doi:10.1002/wps.20550.

Jacobson, N, C., Jacobson, M. S., Weingarden, H., \& Sabine Wilhelm, S. (2019). Using Digital Phenotyping to Accurately Detect Depression Severity. The Journal of Nervous and Mental Disease, 207(10), 893-896.

Jain, S. H., Powers, B. W., Hawkins, J. B., \& Brownstein, J. S. (2015). The digital phenotype. Nature Biotechnology. 33(5), 462-463. doi:10.1038/nbt.3223.

Kleiman, E. M., Turner, B. J., Fedor, S., Beale, E., Picard, R., Huffman, J. C., \& Nock, M. K. (2018). Digital phenotyping of suicidal thoughts. Depression and Anxiety, 35(7), 601-608. doi:10.1002/da.22730.

Lévy, P. (2000). Cibercultura. Rio de Janeiro, RJ: Editora 34.

Mota, N. B., Copelli, M., \& Ribeiro, S. (2017). Thought disorder measured as random speech structure classifies negative symptoms and schizophrenia diagnosis 6 months in advance. npj Schizophr 3, 18. https://doi.org/10.1038/s41537-0170019-3.

Mota, N., Copelli, M., \& Ribeiro, S. (2019). Early Markers of Thought Disorganization. Speech Structure Schizophrenia Bulletin, 45, Issue Supplement_2, S128-S129, https://doi.org/10.1093/schbul/sbz022.098.

Potier, R. (2020). The Digital Phenotyping Project: A Psychoanalytical and Network Theory Perspective. Frontiers in Psychology, 11, 1218.

Ramirez, A. (2020). The Alchemy of Us: How Humans and Matter Transformed One Another. Cambridge, Massachusetts/London, England. The MIT Press. 


\section{ARTIGOS}

Sperling, R., Mormino, E., \& Johnson, K. (2014) The evolution of preclinical Alzheimer's disease: implications for prevention trials. Neuron 84, 608-622.

Stanghellini, G., \& Leoni, F. (2020) Digital Phenotyping: Ethical Issues, Opportunities, and Threats. Front. Psychiatry 11, 473. doi: 10.3389/ fpsyt.2020.00473.

\section{Resumos}

(Digital technologies, subjectivity and psychopathology: possible impacts of the pandemic)

The present article addresses the use of digital technologies in current psychiatry, discussing the impact of technical devices on the social horizon, beyond the limits of the clinical field. Our analysis focuses of the digital phenotyping project, its scope and the challenges it poses for the psychiatric field.

Key words: digital phenotyping, technologies and subjectivity, computational psychiatry, psychiatric diagnosis

(Technologies numériques, subjectivité et psychopathologie: impacts possible de la pandémie)

Cet article discute l'utilisation des technologies numériques en psychiatrie contemporaine, soit l'impact des dispositifs techniques sur l'horizon social au-delà des limites de la clinique. Il se concentre sur l'analyse du projet de phénotypage numérique, sa portée et les défis qu'il pose au domaine psychiatrique.

Mots clés: Phénotypage numérique, technologies et subjectivité, psychiatrie computationnelle, diagnostic psychiatrique

(Tecnologías digitales, subjetividad y psicopatología: posibles impactos de la pandemia)

El artículo aborda el uso de las tecnologías digitales en la psiquiatría actual, discutiendo el impacto de los dispositivos técnicos en el horizonte social más allá de los límites de la clínica, enfocándose en el análisis del proyecto de fenotipado digital, su alcance y los desafios que plantea para el campo psiquiátrico.

Palabras clave: Fenotipado digital, tecnologías y subjetividad, psiquiatría computacional, diagnóstico psiquiátrico 
Citação/Citation: Bezerra Jr., B. (2020, setembro). Tecnologias digitais, subjetividade e psicopatologia: possíveis impactos da pandemia. Revista Latinoamericana de Psicopatologia Fundamental, 23(3), 495-508. http://dx.doi.org/10.1590/1415-4714.2020v23n3p495.4.

Editora/Editor: Profa. Dra. Ana Maria G. R. Oda e Profa. Dra. Sonia Borges

Submetido/Submitted: 20.8.2020 / 8.20.2020 Aceito/Acepted: 22.8.2020 / 8.22.2020

Copyright: (C) 2009 Associação Universitária de Pesquisa em Psicopatologia Fundamental/ University Association for Research in Fundamental Psychopathology. Este é um artigo de livre acesso, que permite uso irrestrito, distribuição e reprodução em qualquer meio, desde que o autor e a fonte sejam citados / This is an open-access article, which permits unrestricted use, distribution, and reproduction in any medium, provided the original authors and sources are credited.

Financiamento/Funding: Este trabalho não recebeu apoio / This work received no funding.

Conflito de interesses/Conflict of interest: $\mathrm{O}$ autor declara que não há conflito de interesses. / The author declares that there is no conflict of interest.

\section{Benilton Bezerra JR.}

Universidade do Estado do Rio de Janeiro - UERJ (Rio de Janeiro, RJ, Brasil)

Av. Rui Barbosa, 300/402 - Flamengo

22250-020 Rio de Janeiro, RJ, Br

beniltonjr@gmail.com

https.//orcid.org/0000-0001-8557-537X

This is an open-access article, which permits unrestricted use, distribution, the original authors and sources are credited. 